\title{
Ação de inibidores de enzimas oxidativas e crescimento bacteriano sobre a longevidade das flores de ave-do-paraíso (Strelitzia reginae Aiton) ${ }^{(1)}$
}

\author{
ANA ERMELINDA MARQUES ${ }^{(2)}$, FERNANDA SILVA(3), JOSÉ GERALDO BARBOSA ${ }^{(4)}$ \\ E FERNANDO LUIZ FINGER(4)
}

\begin{abstract}
RESUMO
Com o objetivo de avaliar a eficiência de inibidores das enzimas polifenoloxidase e peroxidase, além da participação do crescimento bacteriano nas hastes florais de ave-do-paraíso, soluções de vaso contendo inibidores das enzimas polifenoloxidase e peroxidase foram aplicadas em sistema de pulso. Foram feitos dois experimentos: no primeiro foram aplicados 2-mercaptoetanol $10 \mathrm{mM}$, catecol $5 \mathrm{mM}, p$-nitrofenol $5 \mathrm{mM}$, metabissulfito de sódio $10 \mathrm{mM}$ e água destilada, sem a correção do $\mathrm{pH}$, o segundo foi feito com os mesmos tratamentos acima, porém com o pH ajustado para 6,0. A atividade das enzimas oxidativas foi determinada a cada 48 horas até a senescência dos floretes, quando foi então avaliada a contagem total de bactérias presentes na porção basal da haste. O metabissulfito de sódio $10 \mathrm{mM}$ resultou na maior redução da atividade das enzimas no segundo dia após a aplicação, comparado com os demais inibidores. Em todos os tratamentos, em ambos os experimentos, a população bacteriana foi elevada contribuindo para a obstrução física das hastes.
\end{abstract}

Palavras-chave: oclusão vascular, polifenoloxidase, peroxidase, microorganismos.

\section{ABSTRACT}

Action of inhibitors on oxidative enzymes and bacterial growth on longevity the bird-of-paradise (Strelitzia reginae Aiton) flowers

\begin{abstract}
With the intent of evaluating the efficiency of inhibitors of polyphenol oxidase and peroxidase, besides the participation of bacterial growth that might take place at the base of the stem of bird-of-paradise, postharvest solutions containing inhibitors polyphenoloxidase and peroxidase were applied. Two experiments were conducted. In the first, the floral stem was pulsed with $10 \mathrm{mM}$ 2-mercaptoethanol, $5 \mathrm{mM}$ catechol, $5 \mathrm{mM}$-nitrophenol, $10 \mathrm{mM}$ sodium metabisulphite and distilled water without $\mathrm{pH}$ adjustment, in another experiment the $\mathrm{pH}$ of the solutions was adjusted for 6.0. The floral stem of each treatment was evaluated at every 48 hours until the end of the longevity of the florets, for both enzymes activities and bacterial growth. The activity of the polyphenoloxidase and peroxidase measured from the second to the eighth day after harvest showed that $10 \mathrm{mM}$ sodium metabisulphite resulted in the highest reduction of enzymes activities at the second day of analysis. In all treatments in both experiments, the bacterial population was high contributing to physical obstruction of the stems.
\end{abstract}

Keywords: vascular occlusion, polyphenoloxidase, peroxidase, microorganisms.

\section{INTRODUÇÃO}

Entre as flores tropicais de corte, a ave-do-paraíso (Strelitzia reginae Aiton) destaca-se como uma das mais atrativas, visto que possui inflorescência com sépalas alaranjadas e pétalas azuis em forma de seta. Os floretes se abrem sucessivamente dentro de uma bráctea de cor verdeavermelhada (CASTRO, 1995; LORENZI e SOUZA, 2001).

Nesta espécie, há perda gradual na condutividade hidráulica quando a inflorescência é acondicionada em vasos, limitando a vida pós-colheita. $\mathrm{O}$ corte na base das hastes florais, a cada dois dias, mantém os tecidos das sépalas hidratados, porém as não cortadas apresentam declínio no conteúdo de água, com consequente diminuição da longevidade e do número de floretes abertos (CAMPANHA et al., 1997). Este resultado sugere a presença de bloqueio vascular na base da haste, porém a causa da obstrução ainda não é conhecida.

A condutância hidráulica do xilema pode ser afetada por microorganismos que crescem na região cortada, obstruindo fisicamente os seus condutos devido ao aumento da população microbiana, à produção de materiais oriundos de seus processos metabólicos, ou pela liberação de substâncias do tecido da planta quando se dá a colonização (TYREE e SPERRY, 1989; VAN DOORN, 1997). O declínio

\footnotetext{
(1) Recebido para publicação em 11/04/2010 e aceito em 12/05/2011.

(2) Parte da Dissertação de Mestrado do Primeiro autor. Recebido para publicação em 26/08/2009 e aceito em 06/05/2011.

(3) Mestrando em Fitotecnia, ESALQ/USP - Email: nelson.sakamoto@sakata.com.br.

(4) Professora e Pesquisadora do Centro de Tecnologia e Análise do Agronegócio- UCDB, Campo Grande, MS Avenida Tamandaré, 8000, CeTeAgro/

UCDB, Instituto São Vicente, Campo Grande - MS, 79 117-900. - Email: cereda@ucdb.br.

(5) Professor do Departamento de Fitotecnia, ESALQ/USP - Email: roberval_ribeiro@hotmail.com.
} 
na absorção da água do vaso também decorre da ação das enzimas peroxidase e polifenoloxidase na região cortada das hastes florais (VAN DOORN e CRUZ, 2000; VAN DOORN e VASLIER, 2002). A atividade dessas enzimas deve-se ao ferimento no tecido, catalisando a síntese de compostos como a lignina e a suberina, obstruindo os vasos condutores do xilema (VAN HUYSTEE, 1987; VAN DOORN, 1997).

A longevidade de diversas espécies de flores pode ser aumentada quando se utilizam compostos químicos capazes de inibir a atividade da polifenoloxidase e da peroxidase, os quais podem atuar diretamente sobre as enzimas ou sobre os intermediários da reação. Em flores de Bouvardia, a aplicação de 4-hexilresorcinol aumentou de 3 para 21 dias a longevidade das flores, mostrando-se um bom inibidor da polifenoloxidase (VASLIER e VAN DOORN, 2003). Em flores de crisântemo os inibidores da peroxidase, $p$-fenileno diamida e hidroquinona aumentaram a longevidade em 6 e 8 dias, respectivamente, em relação ao controle (VAN DOORN e VASLIER, 2002).

Em ave-do-paraíso, a influência das enzimas polifenoloxidase e peroxidase bem como do crescimento de microorganismos na água do vaso não foram avaliados. Assim, este trabalho teve como objetivo avaliar a eficiência de inibidores das enzimas polifenoloxidase e peroxidase, além da participação do crescimento bacteriano no corte das hastes durante a vida de vaso de ave-do-paraíso.

\section{MATERIAL E MÉTODOS}

As hastes florais de ave-do-paraíso com o primeiro florete aberto foram colhidas no campo de cultivo do Departamento de Fitotecnia da Universidade Federal de Viçosa, Viçosa (MG). Em seguida, foram levadas ao laboratório, selecionadas, e a base cortada dentro de um recipiente com água destilada, para evitar a entrada de ar nos vasos condutores. O comprimento das hastes foi uniformizado para $80 \mathrm{~cm}$ e distribuídas ao acaso em cada tratamento. Os experimentos foram conduzidos a $25 \pm 5^{\circ} \mathrm{C}$, UR $60 \pm 20 \%$ e $10 \mu \mathrm{mol} \mathrm{s}^{-1} \mathrm{~m}^{-2}$ de luz branca fluorescente.

No primeiro experimento foram utilizados $10 \mathrm{mM}$ de 2-mercaptoetanol, $5 \mathrm{mM}$ de $p$-nitrofenol, $10 \mathrm{mM}$ de metabissulfito de sódio, $5 \mathrm{mM}$ de catecol (VAN DOORN e VASLIER, 2002) e água destilada, como controle. Esses produtos químicos, quando adicionados à água, reduzem o pH para valores abaixo de 5,0. Nesse experimento, não houve ajustamento do $\mathrm{pH}$. Um segundo experimento foi realizado, visto que em valores de $\mathrm{pH}$ abaixo de 5,0 há inibição das enzimas oxidativas. As soluções foram preparadas com os mesmos produtos descritos e nas mesmas concentrações, entretanto o $\mathrm{pH}$ de cada solução foi ajustado para 6,0, com $0,1 \mathrm{M}$ de $\mathrm{NaOH}$. As soluções foram aplicadas por um período de 5 horas em sistema de pulso, em seguida, substituídas por água destilada e assim sucessivamente a cada 48 horas até o término da longevidade dos floretes.

As hastes florais foram pesadas obtendo-se a massa fresca inicial (g) (MFI). As novas pesagens feitas a cada troca da água destilada foram para obter a massa fresca final (g) (MFF). Os resultados foram expressos em porcentagem de matéria fresca $(\mathrm{PMF})$, sendo PMF $(\%)=[(\mathrm{MFF} / \mathrm{MFI})]$ x 100. Ao primeiro peso, atribuiu-se o valor de $100 \%$ (MIZOBUTSI, 2003).

A contagem do número de floretes abertos foi feita a cada 48 horas após o início dos tratamentos até o término da longevidade do último florete aberto. A longevidade foi avaliada de acordo com a abertura e senescência dos floretes. O término da vida pós-colheita da haste floral ocorreu quando o último florete aberto ficou murcho (CAMPANHA et al., 1997).

$\mathrm{O}$ teor relativo de água (TRA) foi determinado em cinco discos das sépalas dos floretes com um furador de $12 \mathrm{~mm}$ de diâmetro, pesados e colocados para hidratar em espuma de poliuretano com furos de $14 \mathrm{~mm}$ de diâmetro. A espuma foi saturada com água destilada e colocada em recipiente envolvido com embalagem plástica, mantendose a atmosfera úmida (CAMPANHA et al., 1997). O teor relativo de água foi determinado a cada 48 horas e calculado de acordo com a fórmula descrita por CATSKY (1974).

Os ensaios enzimáticos foram realizados com amostras de aproximadamente $2 \mathrm{~cm}$ de comprimento obtidas da base das hastes florais. As amostras foram congeladas em nitrogênio líquido e armazenadas a temperatura de $-20^{\circ} \mathrm{C}$. As extrações foram feitas com almofariz e pistilo previamente resfriados. O homogenato resultante foi centrifugado a $17000 \mathrm{~g}$, por 15 minutos, a $4{ }^{\circ} \mathrm{C}$. O sobrenadante foi coletado e usado para quantificação da proteína total (BRADFORD, 1976) e atividades polifenoloxidase (PPO) e peroxidase (POD).

Para a extração da polifenoloxidase, foram utilizados $4 \mathrm{~mL}$ de meio contendo $20 \mathrm{mM}$ de tampão fosfato de sódio, $\mathrm{pH} 6,8,1 \%$ de polivinilpirrolidona e $1 \%$ de Triton X-100 (UNDERHILL e CRITCHLEY, 1995). A atividade da polifenoloxidase foi determinada de acordo com AQUINO-BOLAÑOS e MERCADO-SILVA (2004), com algumas modificações. O ensaio enzimático foi realizado em espectrofotômetro, após a adição de $150 \mu \mathrm{L}$ de extrato enzimático ao meio de reação contendo $2,75 \mathrm{~mL}$ de 0,2 M tampão fosfato, pH 7,0 e $100 \mu \mathrm{L}$ de $60 \mathrm{mM}$ de catecol. A atividade da enzima foi determinada a $420 \mathrm{~nm}$, durante 2,5 minutos, a $25{ }^{\circ} \mathrm{C}$. A atividade da polifenoloxidase foi expressa em unidades de absorbância (UA) $\mathrm{min}^{-1} \mathrm{mg}^{-1} \mathrm{de}$ proteína.

A peroxidase foi extraída com $4 \mathrm{~mL}$ de meio de extração que continha $0,1 \mathrm{M}$ de tampão fosfato de sódio $\mathrm{pH} 6,5$, $0,1 \%$ de bissulfito de sódio e $0,15 \mathrm{M}$ de cloreto de sódio (MENOLLI et al., 2008). Para os ensaios de atividade da peroxidase, $250 \mu \mathrm{L}$ do extrato enzimático foram aplicadas a $3 \mathrm{~mL}$ de meio de reação contendo $1,5 \mathrm{~mL}$ de $0,1 \mathrm{M}$ de tampão fosfato de sódio, $\mathrm{pH}$ 6,5, 0,5 $\mathrm{mL}$ de $190 \mathrm{mM}$ de guaiacol, $0,5 \mathrm{~mL}$ de $10 \mathrm{mM}$ de $\mathrm{H}_{2} \mathrm{O}_{2}$ e $250 \mu \mathrm{L}$ de água deionizada. As reações foram acompanhadas em espectrofotômetro pela variação da absorbância no comprimento de onda de 470 $\mathrm{nm}$, durante 2,5 minutos, a $25^{\circ} \mathrm{C}$, imediatamente após a mistura. A atividade enzimática foi expressa em unidades de absorbância (UA) $\mathrm{min}^{-1} \mathrm{mg}^{-1}$ de proteína.

A contagem das unidades formadoras de colônias (UFCs) foi realizada por meio do método de diluição em placas das células bacterianas viáveis em suspensão. Para o semeio e crescimento das bactérias, usou-se o Meio 523 de Kado e Heskett (ROMEIRO, 2001). A suspensão de células bacterianas foi obtida pela maceração de $0,5 \mathrm{~cm}$ da base das 
hastes florais, usando $20 \mathrm{~mL}$ de solução de extração de 0,05 M de tampão fosfato, $\mathrm{pH}$ 7,0 e 1\% de polivinilpirrolidona. Em seguida, fez-se a diluição em série da suspensão de células bacterianas, usando $0,05 \mathrm{M}$ de tampão fosfato, $\mathrm{pH}$ 7,0. Procedeu-se à incubação por um período de 24 a 72 horas e calcularam-se as UFCs por mililitro.

O delineamento experimental foi em blocos casualizados, com três repetições, sendo que cada recipiente continha no mínimo cinco hastes florais. Os dados foram submetidos à ANOVA, e as médias comparadas pelo teste de Tukey a $5 \%$ de probabilidade. Os dados também foram submetidos à análise estatística descritiva de médias e erro padrão da média.

\section{RESULTADOS E DISCUSSÃO}

A atividade da polifenoloxidase, a partir do segundo dia após a colheita, foi semelhante em todos os tratamentos, com exceção do $10 \mathrm{mM}$ de metabissulfito de sódio, que promoveu efeito inferior aos demais tratamentos ao longo da vida de vaso (Figura $1 \mathrm{~A})$. Embora o metabissulfito e o 2-mercaptoetanol tenham semelhante mecanismo de ação sobre a polifenoloxidase, $10 \mathrm{mM}$ de 2-mercaptoetanol não reduziram a atividade da PPO no segundo dia após a colheita, tendo a atividade sido praticamente a mesma em todos os dias analisados (Figura $1 \mathrm{~A}$ ).

O 2-mercaptoetanol é um retardante da oxidação de compostos biológicos em soluções e, assim, sua atuação provavelmente deve ter ocorrido sobre as $o$-quinonas produzidas pela PPO, reduzindo-as. No segundo dia após a colheita, não houve pigmentação na região cortada das hastes florais. Contudo, nos demais dias, a cada corte realizado, houve pigmentação, conforme ocorreu para a água destilada (Figura 5 A). NEGISHI e OZAWA (2000) extraíram e purificaram parcialmente a PPO de Rhododendron mucronatum e observaram redução na formação de compostos intermediários da reação quando se usou a epicatequina como substrato, indicando, portanto, a ação redutora do 2-mercaptoetanol ao inibir a polimerização das $o$-quinonas. Em semente de girassol, a atividade da PPO teve redução parcial de $69,1 \%$ quando se usou 0,05 mM de 2-mercaptoetanol (RAYMOND et al., 1993). Na região de corte das hastes florais tratadas com 2-mercaptoetanol não houve pigmentação até o segundo dia após a colheita (Figura $5 \mathrm{~B}$ ), provavelmente devido ao efeito redutor do 2-mercaptoetanol sobre as quinonas produzidas durante a reação e não sobre a atividade da enzima PPO.

A utilização de catecol a $5 \mathrm{mM}$ não afetou a atividade da PPO ao longo da vida de vaso (Figura 1 A). Catecol é um substrato bastante usado para estudo da caracterização da PPO, semelhante a outros compostos $o$-difenóis como catequina e 4-metilcatecol (SIMSEK e YEMENICIOGLU, 2007). Durante a aplicação do catecol houve formação de intensa pigmentação escura na região do corte, devido à oxidação ocorrida ao longo das 5 horas de pulso (Figura $5 \mathrm{C}$ ). Nas hastes mantidas em água destilada (Figura $5 \mathrm{~A}$ ), a pigmentação ocorrida no corte não foi tão intensa como a observada no tratamento com catecol. No presente trabalho, o catecol não elevou a atividade da PPO, mas pode ter induzido a formação da melanina em resposta à injúria mecânica da colheita das hastes.

A aplicação de $5 \mathrm{mM}$ de $p$-nitrofenol não afetou a atividade da PPO, comparado com a água destilada (Figura 1 A). Na base das hastes florais, observou-se aspecto de encharcamento no tecido. Assim, a concentração $5 \mathrm{mM}$ usada pode ter sido fitotóxica e, por conseqüência, causado dano ao tecido (Figura 5 D). VAN DOORN e VASLIER (2002) verificaram efeito positivo do $p$-nitrofenol a 5 $\mathrm{mM}$ como solução pós-colheita para crisântemo, pois o tempo para que houvesse murcha da inflorescência foi retardado em aproximadamente cinco dias em relação ao controle. Esse efeito não foi observado em ave-do-paraíso, e presença de fitotoxidez na base das hastes sugere que a concentração e o tempo de aplicação do $p$-nitrofenol devem ser reavaliados para esta espécie.

O tratamento com $10 \mathrm{mM}$ de metabissulfito de sódio reduziu em 78\% a atividade da PPO comparada às hastes controle, no segundo dia após colheita. Nos dias restantes, a atividade foi superior à do segundo dia, porém inferior à água destilada e aos demais tratamentos (Figura 1 A). Conforme foi observado no tratamento com o 2-mercaptoetanol, não houve formação de pigmentos no tecido cortado até o segundo dia após a colheita com o uso do metabissulfito de sódio (Figura 5 E). A atividade da PPO relaciona-se com danos causados às plantas por ataque de herbívoros, patógenos e processamento (ARAÚJO, 2004; MAYER, 2006). As raízes de jicama, quando processadas, apresentaram altos valores de fenóis ao longo dos dias de armazenamento em resposta ao dano mecânico causado ao tecido, indicando que o seu escurecimento é devido à atividade da PPO (AQUINO-BOLAÑOS e MERCADOSILVA, 2004). Na caracterização da PPO de extrato bruto de taro, o metabissulfito de sódio em concentrações de $0 ; 0,5$; 1,0 e 2,5 mM inibiu a atividade da enzima, em condições de pré-incubação, o que não ocorreu com a atividade da PPO em batata (DUANGMAL e APENTEN, 1999). As PPOs catalisam reações de óxido-redução dos compostos fenólicos, transformando-os em quinonas correspondentes (MAYER, 2006). As quinonas podem polimerizar-se e formar pigmentos insolúveis escuros denominados melanina ou reagir não enzimaticamente com outros compostos fenólicos, aminoácidos e proteínas, formando também melanina (ARAÚJO, 2004). De igual forma, as hastes florais quando cortadas têm tecido exposto, e a atividade de enzimas oxidativas altera o aspecto do local cortado, depreciando o produto.

A atividade da enzima peroxidase (POD) foi analisada em ave-do-paraíso de forma semelhante ao descrito para a PPO. Nos ensaios realizados, o uso de $10 \mathrm{mM}$ de 2-mercaptoetanol reduziu a atividade da enzima em torno de $41,41 \%$ no segundo dia analizado, comparado aos demais dias em que as atividades estavam elevadas e semelhantes entre si (Figura 1 B). O 2-mercaptoetanol, além de ser usado como retardante da oxidação de compostos biológicos em solução, é também apropriado para reduzir ligações dissulfeto de proteínas (SARIRI et al., 2006). Dessa forma, este composto provavelmente agiu reduzindo as quinonas formadas durante a atividade da POD sobre a própria POD, ou sobre outra enzima importante na rota dos compostos fenólicos, a fenilalanina amonialiase. Apesar de a atividade nessa situação ser igual à da água destilada, 
não houve pigmentação no corte. Então, de alguma forma houve atuação do 2-mercaptoetanol, pois, no segundo dia, o valor da atividade da POD foi menor em relação aos outros dias. Na caracterização da peroxidase de rabanete, $80 \mu \mathrm{M}$ de 2-mercaptoetanol e $160 \mu \mathrm{M}$ de ácido mercaptoacético, dois compostos do grupo tiol mostraram-se eficientes na inibição de $50 \%$ da atividade da peroxidase, sugerindo que o mecanismo de ação seria de se ligar no sítio ativo da enzima (SARIRI et al., 2006).

O condicionamento com $5 \mathrm{mM}$ de catecol não causou efeito inibitório sobre a atividade da POD (Figura 1 B), diferindo do observado por DOGAN et al. (2007) ao avaliarem a especificidade de cinco substratos para esta enzima, em três espécies de Salvia, entre eles o catecol e o guaiacol, os quais promoveram atividade da POD, principalmente o guaiacol. Em ave-do-paraíso, a aplicação do catecol apenas em solução pós-colheita não permitiu fazer essa inferência, pois, para isso, é necessário purificar a POD e investigar sua atividade na presença desse composto.

A POD apresentou atividades semelhantes para o tratamento com $5 \mathrm{mM}$ de $p$-nitrofenol nos dias analisados (Figura 1 B). A solução contendo $p$-nitrofenol não exerceu ação inibidora sobre a atividade da POD, concordando com o verificado por VAN DOORN e VASLIER (2002) em hastes de crisântemo. Conforme ocorreu com a PPO, a base das hastes florais apresentou o mesmo aspecto de encharcamento. Assim, devido à fitotoxidez, os danos causados ao tecido, de alguma forma, influenciaram a atividade da POD.

A solução de $10 \mathrm{mM}$ de metabissulfito de sódio reduziu $65 \%$ da atividade da POD no segundo dia da colheita, comparando-se a atividade à da água destilada, sendo que, nos outros dias, foram observados incrementos gradativos (Figura 1 B). Embora seu mecanismo de ação não seja bem conhecido, a interferência na reação pode se dar nas formas de inibição direta sobre a enzima, combinação com quinonas, evitando condensações adicionais ou reduzi-las à forma fenólica inicial (ARAÚJO, 2004).

A capacidade catalítica das enzimas para exercer a função em soluções aquosas depende das condições de temperatura e pH. A mudança no estado de ionização no sítio ativo é uma razão comum para variar a atividade (LEHNINGER et al., 2006). Os compostos $5 \mathrm{mM}$ de catecol, $5 \mathrm{mM}$ de $p$-nitrofenol, $10 \mathrm{mM}$ de metabissulfito de sódio e $10 \mathrm{mM}$ de 2-mercaptoetanol aplicados no primeiro experimento para análise da atividade da PPO e da POD alteraram o pH das soluções para valores menores que 5,0. No segundo experimento, foram utilizados os mesmos compostos e as mesmas concentrações, mas com o $\mathrm{pH}$ das soluções ajustado para 6,0. No experimento com ajuste de $\mathrm{pH}$, foi detectada redução de $75 \%$ da atividade da PPO no segundo dia após a colheita, em relação ao controle, com a aplicação de $10 \mathrm{mM}$ de metabissulfito de sódio (Figura $2 \mathrm{~A}$ ). Com a POD, ocorreu efeito inibitório de aproximadamente $50 \%$ com $10 \mathrm{mM}$ de 2-mercaptoetanol, e de $77 \%$ com o $10 \mathrm{mM}$ de metabissulfito de sódio, comparado ao controle, conforme observado no segundo dia de análise (Figura 2 B). Verifica-se, portanto, que o 2-mercaptoetanol, de alguma forma atuou sobre a atividade da peroxidase e da polifenoloxidase no segundo experimento.
Nos tratamentos com 2-mercaptoetanol, catecol, $p$-nitrofenol e água destilada, as atividades da PPO mostraram variações do segundo dia após a colheita até o oitavo dia em relação ao primeira experimento (Figura 2 A). Situação semelhante ocorreu com a POD, com exceção do 2-mercaptoetanol e do metabissulfito, no segundo dia, nesse segundo experimento (Figura 2 B). Quanto ao aspecto do tecido na região cortada, as soluções causaram os mesmos efeitos sem o ajuste de seus respectivos $\mathrm{pHs}$, indicando que ele não teve efeito maior do que a ação das substâncias na base das hastes. Em ambos os experimentos, verificou-se eficiência do $10 \mathrm{mM}$ metabissulfito de sódio em reduzir a atividade tanto da PPO quanto da POD até o segundo dia da colheita.

A enzima peroxidase apresenta importantes funções fisiológicas na planta, como a ligação entre os componentes $o$-difenil na parede celular e a polimerização de ligninas e suberinas (HERNÁNDEZ-RUIZ et al., 2000). Diante dos ensaios com a POD, verificou-se que essa enzima assim como a PPO exibem atividade em ave-do-paraíso associada à proteção da região cortada quando a haste é colhida para a comercialização.

$\mathrm{Na}$ aplicação das soluções de condicionamento sem a correção do $\mathrm{pH}$, a maior elevação na matéria fresca foi obtida com a aplicação do metabissulfito de sódio a 10 $\mathrm{mM}, 106,3 \%$ (Figura 3). Com exceção da água destilada e do catecol a $5 \mathrm{mM}$, que tiveram o peso da matéria fresca em torno de $102 \%$, o $p$-nitrofenol a $5 \mathrm{mM}$ e o 2 -mercaptoetanol a $10 \mathrm{mM}$ mantiveram os valores próximos de $104 \%$. Nas soluções que tiveram seus pHs ajustados para 6,0 (Figura 4), o peso da matéria fresca foi semelhante ao dos tratamentos aplicados sem correção do $\mathrm{pH}$, apresentando também o maior valor, $106,5 \%$, para o metabissulfito de sódio a 10 $\mathrm{mM}$. Com ou sem a correção do $\mathrm{pH}$ das soluções, verificouse queda brusca do peso da matéria fresca das hastes florais entre o segundo e o quarto dia da colheita, que se manteve praticamente estável até o oitavo dia. O estresse hídrico que se instalou logo após o segundo dia da colheita coincide com a elevada atividade das enzimas PPO e POD. A atividade dessas enzimas é uma resposta ao ferimento feito no tecido em decorrência do corte. Tanto a PPO como a POD são ativadas quando a planta passa por estresses que produzem danos aos tecidos (VAN HUYSTEE, 1987; MAYER, 2006).

O teor relativo de água (TRA) das sépalas dos floretes não mostrou diferença significativa $(\mathrm{P}>0,05)$ entre os tratamentos aplicados. No experimento1, a média geral do TRA foi de $67 \%$ e na etapa 2 de $69 \%$. Os valores baixos do TRA em cada tratamento expressam a restrição hídrica sofrida pelas sépalas, devido à baixa condutividade hidráulica do xilema ao longo dos dias após a colheita, também evidenciada pela redução do peso da matéria fresca das hastes florais.

A senescência em flores de gladíolo ocorreu à medida que o conteúdo de água de suas sépalas (TRA) decrescia gradualmente, correspondendo à diminuição do seu peso fresco no período analisado (HOSSAIN et al., 2006).

Nos experimentos 1 e 2, não houve diferença significativa $(\mathrm{P}>0,05)$ entre os tratamentos para o número de floretes abertos e para a longevidade das hastes florais. A média geral do número de floretes abertos foi de 1,8 para o 
primeiro experimento e de 1,7 para o segundo experimento. As hastes florais tiveram longevidade média de 8,9 e 8,4 dias, para os experimentos 1 e 2 , respectivamente.

Não houve diferença significativa entre os tratamentos aplicados no primeiro experimento $(\mathrm{P}>0,05)$ com média geral da população bacteriana de $7,72 \times 10^{6} \mathrm{UFC} / \mathrm{mL}$. No segundo experimento, houve diferença significativa $(\mathrm{P}<0,05)$ na contagem da população bacteriana (Tabela 1), porém todos os tratamentos apresentaram valores superiores a $10^{6} \mathrm{UFC} / \mathrm{mL}$, que são elevados e podem ocasionar obstrução física na base das hastes.

As flores deterioram-se por várias razões, sendo a incapacidade de absorção de água causada por proliferação de microorganismos a mais comum. O bloqueio vascular causado por bactérias é um processo aparentemente físico, portanto, vivas ou mortas, as bactérias formam uma fina camada e juntamente com o material produzido em seu metabolismo cobrem o xilema na superfície cortada (VAN DOORN, 1997).

BLEEKSMA e VAN DOORN (2003) verificaram que a cavitação dos vasos em Rosa hybrida L. aumentou gradualmente com o aumento da população bacteriana, e esse efeito foi mais grave quando a população bacteriana ultrapassou $10^{8} \mathrm{UFC} / \mathrm{mL}$. ICHIMURA et al. (1999) verificaram que a aplicação do germicida sulfato de 8-hidroxiquinolina manteve a condutividade hidráulica próxima do original ao longo dos dias após a colheita em hastes de rosas, devido ao controle dos microorganismos.

As soluções pós-colheita que possuam a característica de controlar os microrganismos devem ser aplicadas para manter a população controlada, de forma que a condutividade hidráulica seja suficiente para manter as hastes florais hidratadas e a vida pós-colheita de ave-doparaíso aumentada.

O metabissulfito de sódio $10 \mathrm{mM}$ resultou na maior redução da atividade das enzimas no segundo dia após a aplicação, comparado com os demais inibidores. A população bacteriana foi elevada nas hastes em ambos os experimentos. Em conjunto, pode-se inferir que a atividade das enzimas oxidativas e o alto número de colônias de bactérias foram responsáveis pela redução do peso da matéria fresca, do teor relativo de água, do número de floretes abertos e da longevidade, promovendo a senescência precoce dos floretes, devido ao estresse hídrico ocorrido pela baixa condutância hidráulica dos elementos de vaso do xilema.

\section{AGRADECIMENTOS}

Ao CNPq, pela concessão da bolsa.

\section{REFERÊNCIAS}

AQUINO-BOLAÑOS, E. N., MERCADO-SILVA, E. Effects of polyphenol oxidase and peroxidase activity, phenolics and lignin content on the browning of cut jicama. Postharvest Biology and Technology, Amsterdam, v.33, n.3, p.275-283, 2004.

ARAÚJO, J. M. A. Química de alimentos: teoria e prática. 3. ed. Viçosa: Universidade Federal de Lavras, 2004. 478p.

BLEEKSMA, H. C., VAN DOORN, W. G. Embolism in rose stems as a result of vascular occlusion by bacteria. Postharvest Biology and Technology, Amsterdam, v.29, n.3, p.334-340, 2003.

BRADFORD, M. M. A rapid and sensitive method for the quantification of microgram quantities of protein utilizing the principle of protein-dye binding. Analitycal Biochemistry, New York, v.72, p.248-254, 1976.

CAMPANHA, M. M., FINGER, F. L., CECON, P. R., BARBOSA, J. G. Waters relations of cut bird-of-paradise (Strelitzia reginae Ait.) inflorescences. Revista Brasileira de Horticultura Ornamental, Campinas, v.3, n.1, p.2731, 1997.

CASTRO, C. E. F. Inter-relações das famílias das zingiberales. Revista Brasileira de Horticultura Ornamental, Campinas, v.1, n.1, p.2-11, 1995.

CATSKY, J. Water content: In: SLAVIK, B. (ed). Methods of studying plant water relations. Berlim:SpringerVerlag, 1974. p.1170-1172.

DOGAN, S., TURAN, P., DOGAN, M., ARSLAN O., ALKAN, M. Variations of peroxidase activity among Salvia species. Journal of Food Engineering, Essex, v.79, n.2, p.375-382, 2007.

DUANGMAL, K., APENTEN, R. K. O. A comparative study of polyphenoloxidases from taro (Colocasia esculenta) and potato (Solanum tuberosum var. Romano). Food Chemistry, London, v.64, n.3, p.351-359, 1999.

HE, S., JOYCE, D. C., IRVING, D. E., FARAGHER, J. D. Stem end blockage in cut Grevillea 'Crimson Yul-lo' inflorescences. Postharvest Biology and Technology, Amsterdam, v.41, n.1, p.78-84, 2006.

HERNÁNDEZ-RUIZ，J., RODRÍGUES-LÓPEZ，J. N., GARCÍA-CÁNOVAS, F., ACOSTA, M., ARNAO, M. B. Characterization of isoperoxidase-B2 inactivation in etiolated Lupinus albus hypocotyls. Biochimica et Biophysica Acta, Amsterdam, v.1478, n.1, p.78-88, 2000.

HOSSAIN, Z., MANDAL, A. K. A., DATTA, S. K., BISWAS, A. K. Decline in ascorbate peroxidase activity - A prerequisite factor for tepal senescence in gladiolus. Journal of Plant Physiology, Stuttgart, v.163, n.2, p.186194, 2006.

ICHIMURA, K., KOJIMA, K., GOTO, R. Effects of temperature, 8-hydroxyquinoline sulphate and sucrose on the vase life of cut rose flowers. Postharvest Biology and Technology, Amsterdam, v.15, n.1, p.33-40, 1999.

LEHNINGER, A. L., NELSON, D. L., COX, M. M. Princípios de bioquímica. 4. ed. São Paulo:Sarvier, 2006. 
1202 p.

LORENZI, H., SOUZA, H. M. de. Plantas ornamentais no Brasil: arbustivas, herbáceas e trepadeiras. Nova Odessa: Plantarum, 2001. 1088p.

MAYER, A. M. Polyphenol oxidases in plants and fungi: Going places? A review. Phytochemistry, New York, v.67, n.21, p.2318-2331, 2006.

MIZOBUTSI, G. P. Envolvimento de peroxidase e de polifenoloxidase no escurecimento pós-colheita do pericarpo de lichia (Litchi chinensis Sonn). Viçosa:Universidade Federal de Viçosa, 2003. 95p. Tese (Doutorado em Fisiologia Vegetal)

MENOLli, L. N., FINGER, F. L., PUIATTI, M., BARBOSA, J. M., BARROS, R. S. Atuação das enzimas oxidativas no escurecimento causado pela injúria por frio em raízes de batata-baroa. Acta Scientiarum. Agronomy, Maringá, v.30, n. 1, p. 57-63, 2008.

NEGISHI, O., OZAWA, T. Inhibition of enzymatic browning and protection of sulfydryl enzymes by thiol compounds. Phytochemistry, New York, v.54, n.5, p.481487, 2000 .

RAYMOND, J., RAKARIYATHAN, N., AZANZA, J. L. Purification and some properties of polyphenoloxidase from sunflower seeds. Phytochemistry, New York, v.34, n.4, p.927-931, 1993.

ROMEIRO, R. da S. Métodos em bacteriologia de plantas. Viçosa: Universidade Federal de Lavras, 2001. 279 p.

SARIRI, R., JAFARIAN, V., SAJEDI, R. H., KHAJEH, $\mathrm{K}$. Inhibition of horseradish peroxidase by thiol type inhibitors: Mercaptoethanol and mercaptoacetic acid. Journal of Molecular Liquids, Amsterdam, v.128, n.1-3, p.175-177, 2006.

SIMSEK, S., YEMENICIOGLU, A. Partial purification and kinetic characterization of mushroom stem polyphenoloxidase and determination of its storage stability in different lyophilized forms. Process Biochemistry, London, v.42, n.6, p.943-950, 2007.

TYREE, M. T., SPERRY, J. S. Vulnerability of xylem to cavitation and embolism. Annual Review of Plant Physiology and Plant Molecular Biology, Palo Alto, v.40, p.19-38, 1989.

UNDERHILL, S. J. R., CRITCHLEY, C. Cellular localization of polyphenol oxidase and peroxidase activity in Litchi chinensis Sonn pericarp. Australian Journal of Plant Physiology, Melbourne, v.22, n.4, p.627-632, 1995.

VAN DOORN, W. G., WITTE, Y. DE, HARKEMA, $H$. Effect of high numbers of exogenous bacteria on the water relations and longevity of cut carnation flowers. Postharvest Biology and Technology, Amsterdam, v.6, n.1-2, p.111-119, 1995.

VAN DOORN, W. G. Water relations of cut flowers. Horticultural Reviews, New York, v.18, p.1-85, 1997.

VAN DOORN, W. G., CRUZ, P. Evidence for a woundinginduced xylem occlusion in stems of cut chrysanthemum flowers. Postharvest Biology and Technology, Amsterdam, v.19, n.1, p.73-83, 2000.

VAN DOORN, W. G., VASLIER, N. Wounding-induced xylem occlusion in stems of cut chrysanthemum flowers: roles of peroxidase and cathechol oxidase. Postharvest Biology and Technology, Amsterdam, v.26, n.3, p.275284, 2002.

VAN HUYSTEE, R. B. Some molecular aspects of plant peroxidase biosynthetic studies. Annual Review of Plant Physiology, v.38, p.205-219, 1987.

VASLIER, N., VAN DOORN, W. G. Xylem occlusion in bouvardia flowers: evidence for a role of peroxidase and cathechol oxidase. Postharvest Biology and Technology, Amsterdam, v.28, n.2, p.231-237, 2003. 

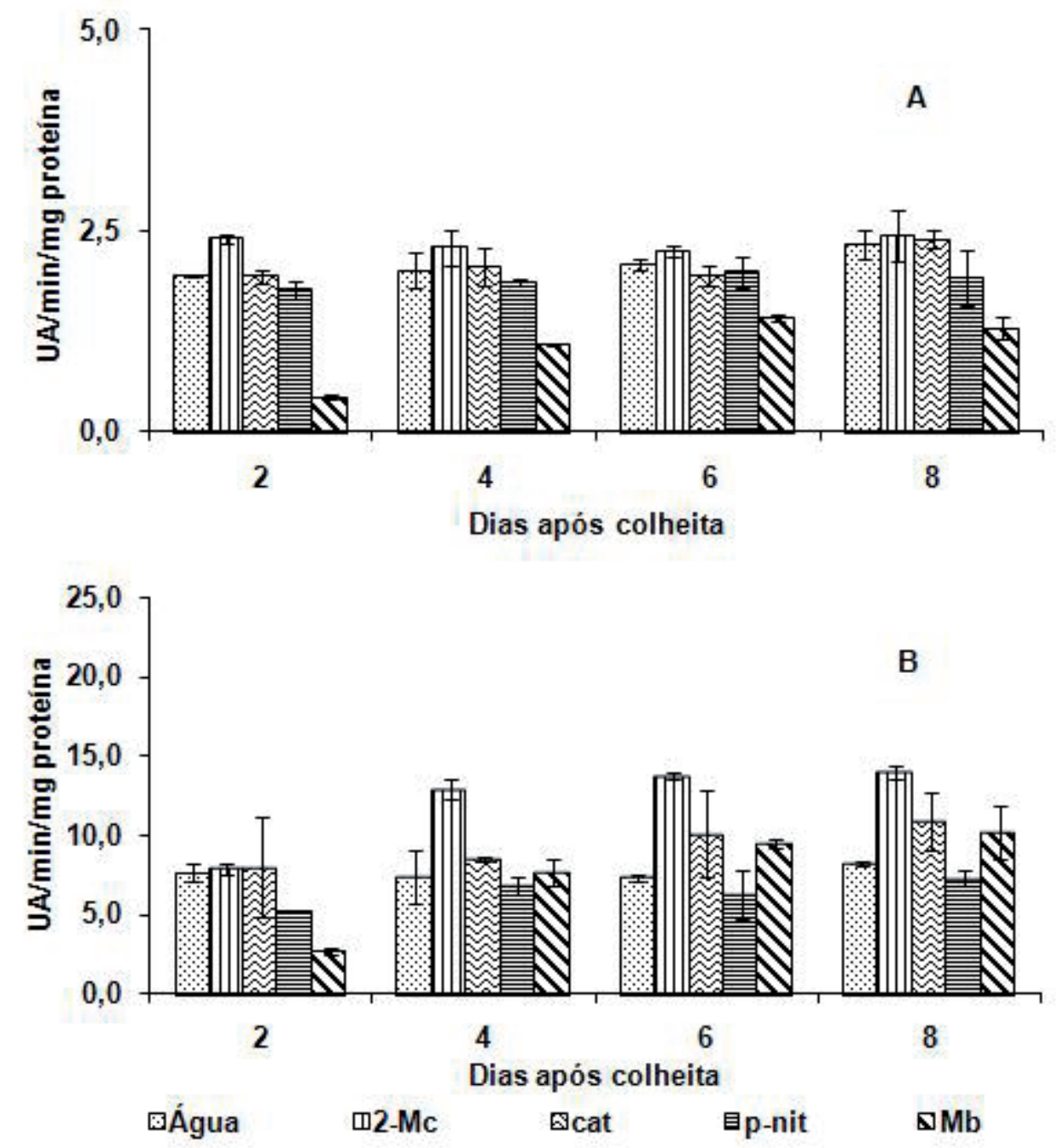

Figura 1. (A) Atividade das enzimas polifenoloxidase e (B) peroxidase (UA/min/mg proteína) em hastes florais de avedo-paraíso. Soluções pós-colheita (sem ajuste do $\mathrm{pH}$, pulso por 5 horas): água destilada (controle), (2-Mc) 2-mercaptoetanol $10 \mathrm{mM}$, (cat) catecol $5 \mathrm{mM}$, (p-nit) p-nitrofenol $5 \mathrm{mM}$, (Mb) metabissulfito de sódio $10 \mathrm{mM}$. As barras verticais representam o erro padrão da média.

Figure 1. (A) Activity of polyphenoloxidase and (B) peroxidase enzymes (UA/min/mg protein) in floral stem of bird-ofparadise. Postharvest solutions (without pH adjustment, pulsing per 5 hours): distilled water (control), (2-Mc) $10 \mathrm{mM}$ 2-mercaptoethanol, (cat) $5 \mathrm{mM}$ catechol, (p-nit) $5 \mathrm{mM}$-nitrophenol, (Mb) $10 \mathrm{mM}$ sodium metabisulfite. The vertical bars plays mean standard error. 

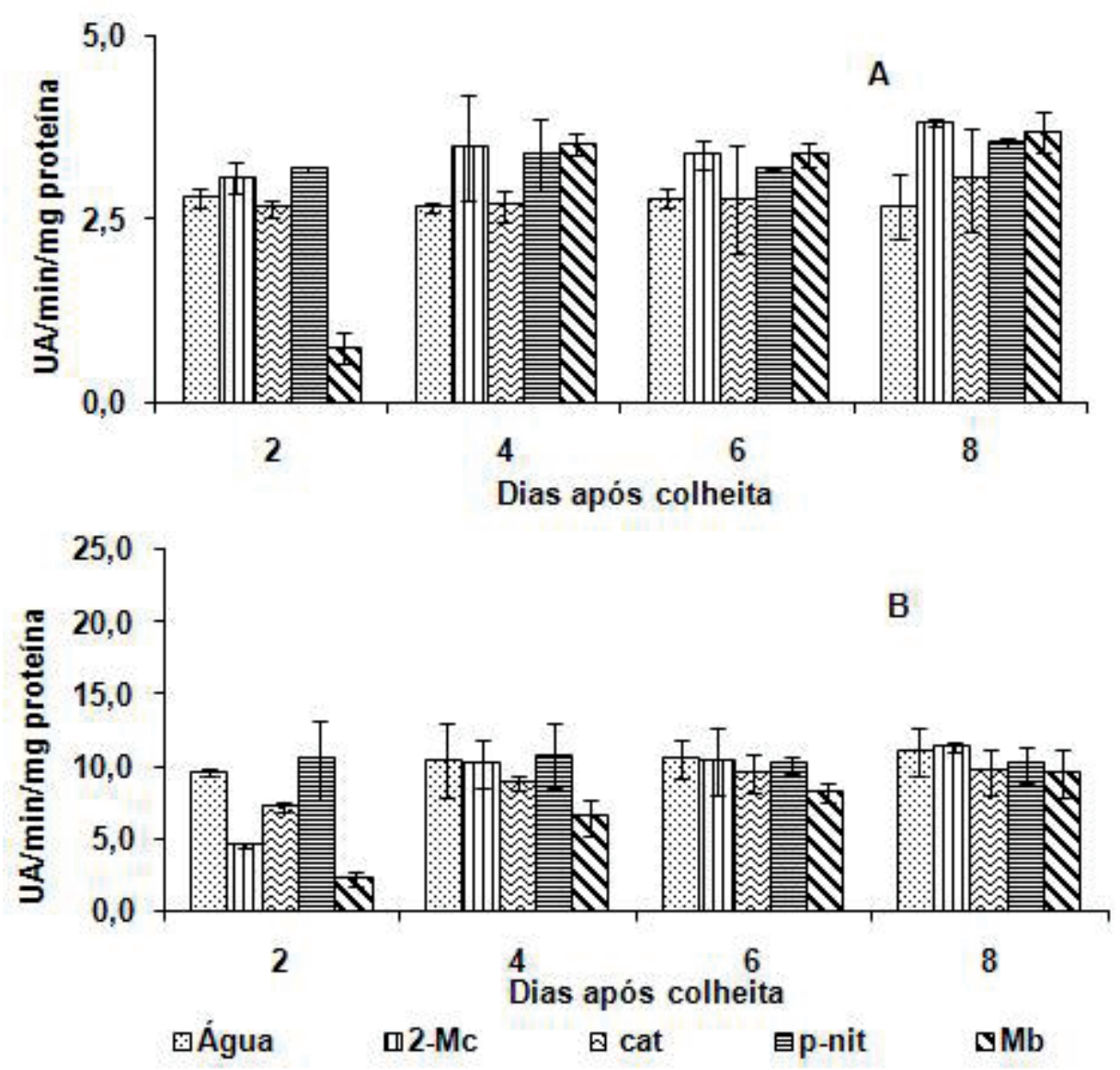

Figura 2. (A) Atividade das enzimas polifenoloxidase e (B) peroxidase (UA/min/mg proteína) em hastes florais de avedo-paraíso. Soluções pós-colheita (pH ajustado para 6,0, pulso por 5 horas): água destilada (controle), (2-Mc) 2-mercaptoetanol $10 \mathrm{mM}$, (cat) catecol $5 \mathrm{mM}$, (p-nit) p-nitrofenol $5 \mathrm{mM}$, (Mb) metabissulfito de sódio $10 \mathrm{mM}$. As barras verticais representam o erro padrão da média.

Figure 2. (A) Activity of polyphenoloxidase and (B) peroxidase enzymes (UA/min/mg protein) in floral stem of birdof-paradise. Postharvest solutions (pH adjusted for 6,0, pulsing per 5 hours): distilled water (control), (2-Mc) $10 \mathrm{mM}$ 2-mercaptoethanol, (cat) $5 \mathrm{mM}$ catechol, (p-nit) $5 \mathrm{mM}$ p-nitrophenol, (Mb) $10 \mathrm{mM}$ sodium metabisulfite. The vertical bars plays mean standard error. 

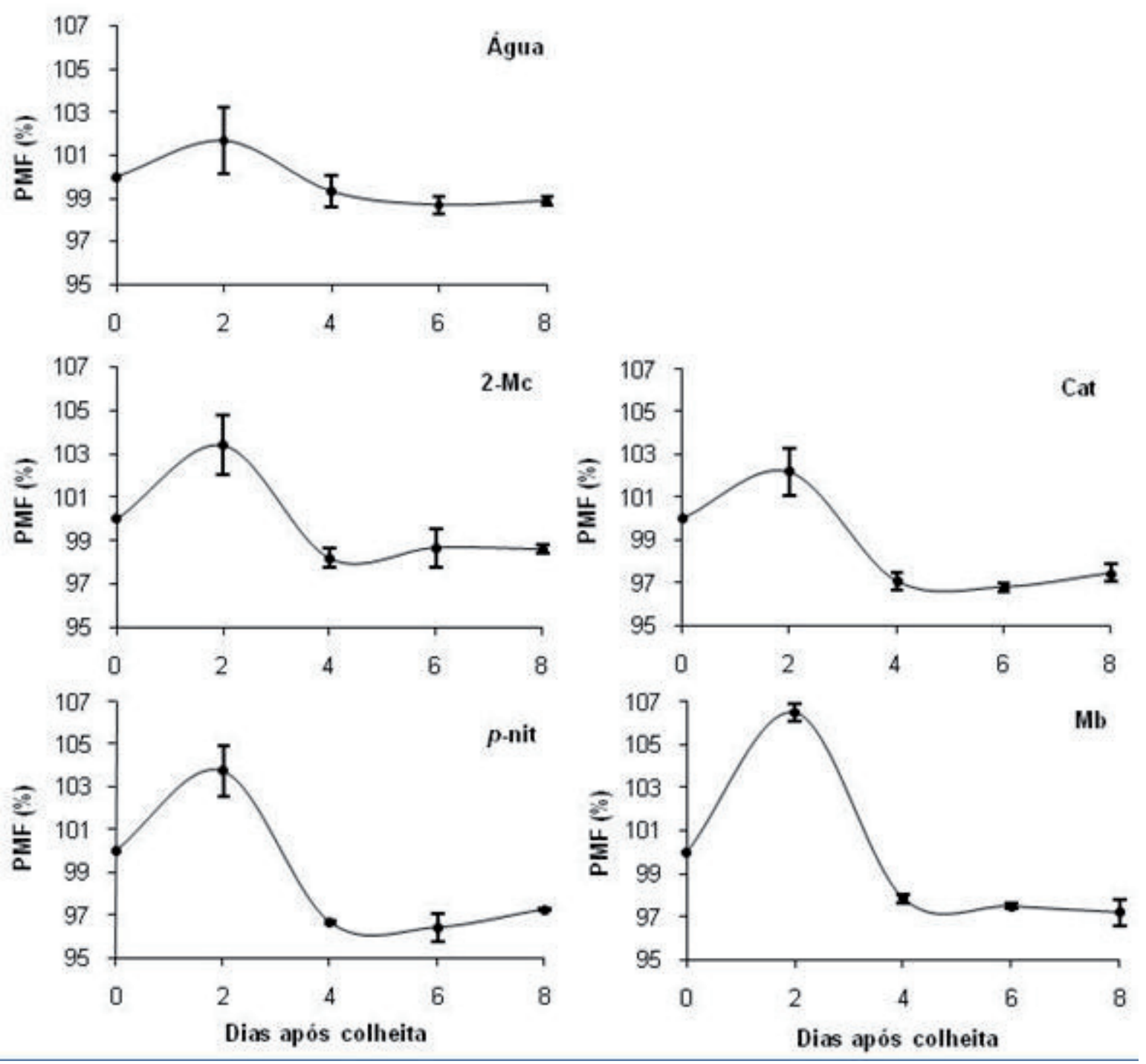

Figura 3. Peso da Matéria Fresca (\%) das hastes florais de ave-do-paraíso. Soluções pós-colheita (sem ajuste do pH, pulso por 5 horas): água destilada (controle), (2-Mc) 2-mercaptoetanol $10 \mathrm{mM}$, (Cat) catecol $5 \mathrm{mM}$, (p-nit) p-nitrofenol $5 \mathrm{mM},(\mathrm{Mb})$ metabissulfito de sódio $10 \mathrm{mM}$. As barras verticais representam o erro padrão da média.

Figure 3. Total Fresh matter (\%) floral stem of bird-of-paradise. Postharvest solutions (without pH adjustment, pulsing per 5 hours): distilled water (control), (2-Mc) $10 \mathrm{mM}$ 2-mercaptoethanol, (Cat) $5 \mathrm{mM}$ catechol, (p-nit) $5 \mathrm{mM} \mathrm{p-nitro-}$ phenol, (Mb) 10 mM sodium metabisulfite. The vertical bars plays mean standard error. 

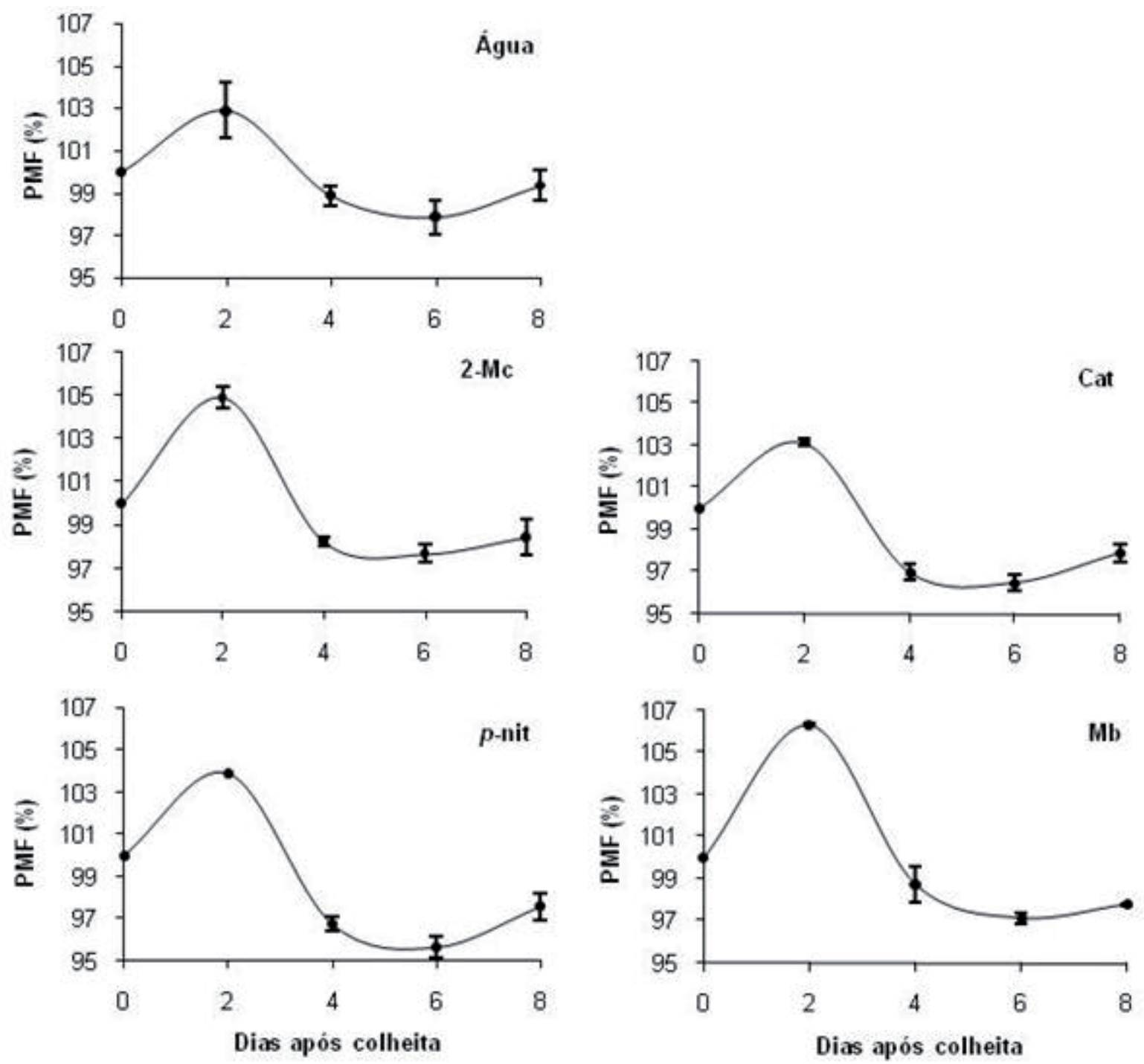

Figura 4. Peso da Matéria Fresca (\%) das hastes florais de ave-do-paraíso. Soluções pós-colheita (pH ajustado para 6,0, pulso por 5 horas): água destilada (controle), 2-mercaptoetanol $10 \mathrm{mM}$ (2-Mc), catecol $5 \mathrm{mM}$ (Cat), p-nitrofenol $5 \mathrm{mM}$ (p-nit), metabissulfito de sódio $10 \mathrm{mM}(\mathrm{Mb})$. As barras verticais representam o erro padrão da média.

Figure 4. Total Fresh Matter (\%) floral stem of bird-of-paradise. Postharvest solutions (pH adjusted for 6,0, pulsing per 5 hours): distilled water (control), $10 \mathrm{mM}$ 2-mercaptoethanol (2-Mc), $5 \mathrm{mM}$ catechol (Cat), $5 \mathrm{mM} \mathrm{p-nitrophenol} \mathrm{(p-nit),}$ $10 \mathrm{mM}$ sodium metabisulfite $(\mathrm{Mb})$. The vertical bars plays mean standard error. 

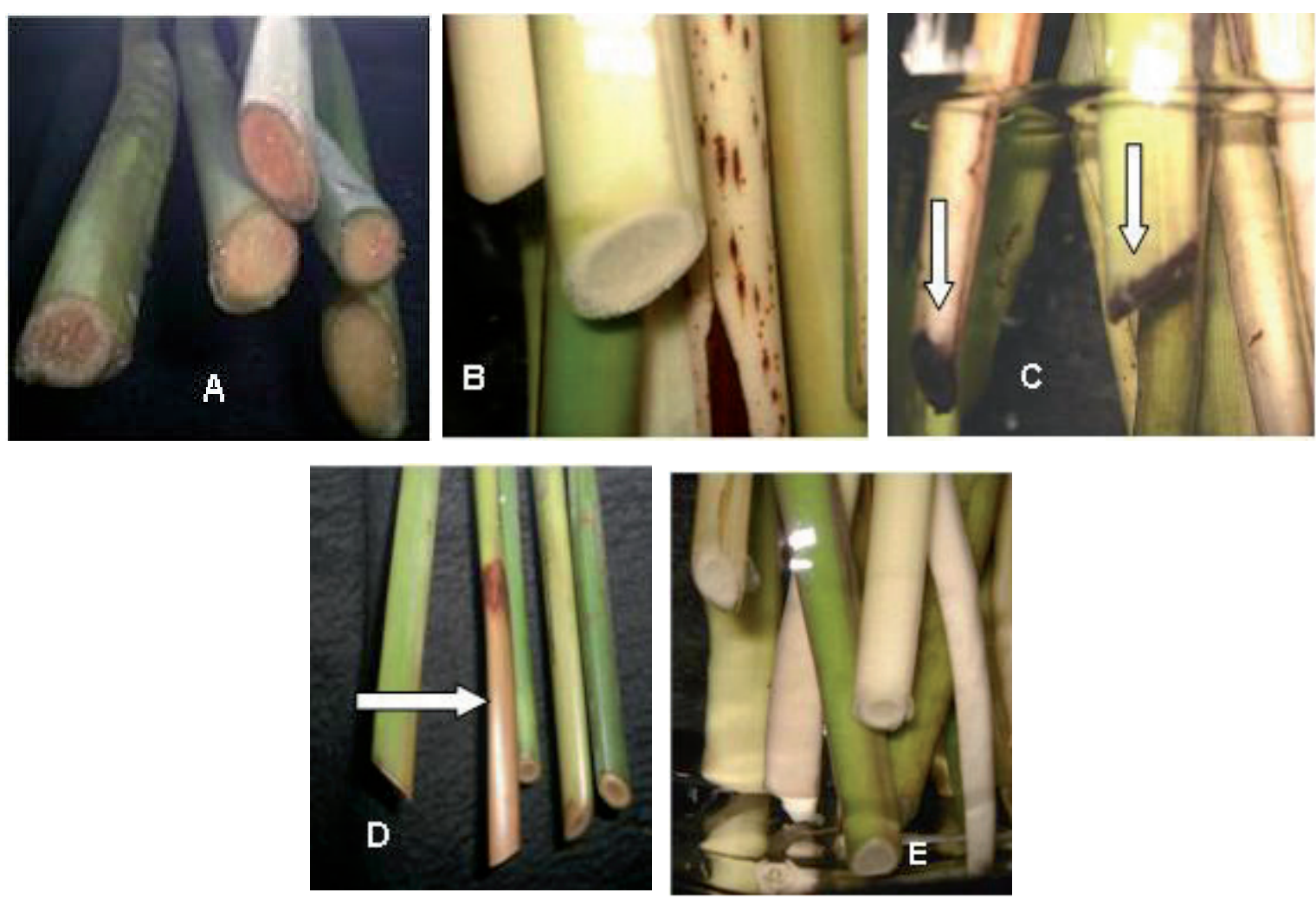

Figura 5. Aspecto do corte das hastes florais de ave-do-paraíso, após a aplicação das soluções pós-colheita: água destilada (A), 2-mercaptoetanol $10 \mathrm{mM}$ (B), catecol $5 \mathrm{mM}$ (C), p-nitrofenol $5 \mathrm{mM}$ (D), metabissulfito de sódio $10 \mathrm{mM}$ (E).

Figure 5. Appearance of floral stem bird-of-paradise after solutions postharvest treatment: distilled water (A), $10 \mathrm{mM}$ 2-mercaptoethanol (B), $5 \mathrm{mM}$ catechol (C), $5 \mathrm{mM}$ p-nitrophenol (D), $10 \mathrm{mM}$ sodium metabisulfite (E).

Tabela 1. População bacteriana na base das hastes florais de ave-do-paraíso na segunda etapa (pH 6,0). Médias seguidas de mesma letra não diferem entre si, a $5 \%$ de probabilidade, pelo Teste de Tukey.

Table 1. Bacterial population in the base of floral stem of bird-of-paradise in the second step (pH 6,0). Averages followed by same letter does not differ by Tukey test at 5\% level of probability.

\begin{tabular}{c|c}
\hline Tratamentos & UFC/mL \\
\hline p-nitrofenol $5 \mathrm{mM}$ & $1,36 \times 10^{7} \mathrm{~A}$ \\
catecol $5 \mathrm{mM}$ & $1,00 \times 10^{7} \mathrm{~A} \mathrm{~B}$ \\
metabissulfito de sodio $10 \mathrm{mM}$ & $3,63 \times 10^{6} \mathrm{~B}$ \\
água destilada & $1,88 \times 10^{6} \mathrm{~B}$ \\
\hline 2-mercaptoetanol $10 \mathrm{mM}$ & $1,84 \times 10^{6} \mathrm{~B}$ \\
\hline
\end{tabular}

